\title{
Associations of Dietary Exposure to Organochlorine Pesticides from Plant-origin Foods with Lipid Metabolism and Inflammation in Childbearing-age Women: A Multiple Follow-up Study in North China
}

\section{Xuepeng Wang}

Beijing Normal University School of Environment

\section{Miaomiao Gao}

Beijing Normal University School of Environment

Yixi Tan

Beijing Normal University School of Environment

Qi Li

Jiangxi Environmental Engineering Vocational College

Junxi Chen

Peking University Institute of Reproductive and Child Health

\section{Changxin Lan}

Peking University Institute of Reproductive and Child Health

\section{Bahabieke Jiangtulu}

Peking University Institute of Reproductive and Child Health

\section{Bin Wang ( $\sim$ binwangpku@foxmail.com )}

Peking University Institute of Reproductive and Child Health https://orcid.org/0000-0002-1164-8430

Yanxin Yu ( $\nabla$ yuhe_f@sina.com )

Beijing Normal University School of Environment

\section{Zhiwen Li}

Peking University Institute of Reproductive and Child Health

\section{Research}

Keywords: OCPs, dietary exposure, lipid metabolism, inflammation

Posted Date: February 22nd, 2021

DOI: https://doi.org/10.21203/rs.3.rs-189884/v1

License: @ (1) This work is licensed under a Creative Commons Attribution 4.0 International License. Read Full License 


\section{Abstract \\ Background}

Potential links between population exposure to organochlorine pesticides (OCPs) and their impact on human health are under discussion. The current study explored the effects of population OCP intake from plant-origin food consumption on lipid metabolism and inflammation using a multiple follow-up study.

\section{Methods}

A total of 10 childbearing-age women (five in urban areas and five in rural areas) in northern China were recruited and visited for five times. During each visit, we conducted a questionnaire survey, blood collection, and food sampling. The levels of OCPs in cereals, fruits, and vegetables were measured, and nutrient content information was obtained from a national monitoring program. We calculated the women's dietary intakes of OCPs and nutrients. Serum biomarkers of lipids [triglycerides, total cholesterol, low-density lipoprotein cholesterol, high-density lipoprotein cholesterol (HDL), and lipoprotein(a)], monocyte chemotactic protein-1, interleukin (IL)-6, and IL-8 were measured. Linear mixed-effect models were used to evaluate the associations of dietary OCP and nutrient intake with serum biomarkers.

\section{Results}

The dietary intake of $p, p^{\prime}$-dichlorodiphenyltrichloroethane (DDT) $[\beta=-10.11,95 \%$ confidence interval $(95 \% \mathrm{Cl}):-17.32,-2.905]$ and $o, p^{\prime}$ dichlorodiphenyldichloroethylene (DDE) $(\beta=-6.077,95 \% \mathrm{Cl}:-9.954,-2.200)$ were overall negatively associated with serum $\mathrm{HDL}$, whereas other OCPs were not. IL-8 was positively associated with intake of dieldrin ( $\beta=0.390,95 \% \mathrm{Cl}: 0.105,0.674)$, endosulfan- $\beta$ ( $\beta=$ $0.361,95 \% \mathrm{Cl}: 0.198,0.523)$, total endosulfan $(\beta=0.136,95 \% \mathrm{Cl}: 0.037,0.234)$, and total OCPs $(\beta=0.084,95 \% \mathrm{Cl}: 0.016,0.153)$, and negatively correlated with intake of $p, p^{\prime}-\mathrm{DDE}(\beta=-2.692,95 \% \mathrm{Cl}:-5.185,-0.198)$. No associations between dietary nutrient intake and serum biomarkers were observed.

\section{Conclusions}

We concluded that dietary intake of some individual DDT-, DDE- dieldrin-, and endosulfan-class chemicals from plant-origin foods may interfere with lipid metabolism and inflammation responses.

\section{Introduction}

Organochlorine pesticides (OCPs) are a group of highly toxic and halogenated organic pollutants that are frequently used in agricultural activities [1]. The best-known chemicals in this group, including aldrin, chlordane, dieldrin, dichlorodiphenyltrichloroethane (DDT), endrin, heptachlor, hexachlorobenzene ( $\mathrm{HCB}), a$-hexachlorocyclohexane $(\mathrm{HCH}), \beta-\mathrm{HCH}$, lindane, mirex, technical endosulfan and its related isomers, and toxaphene, have been categorized as "persistent organic pollutants" under the Stockholm Convention [2]. Mounting evidence indicates that exposure to these contaminants is a significant factor in several long-term adverse health effects, such as metabolic syndrome, immune dysfunctions, and cancers, creating a serious challenge to public health $[3,4]$.

Dyslipidemia is a typical symptom of metabolic disorders [5], characterized by high levels of triglyceride (TG), high total cholesterol (TC), high low-density lipoprotein cholesterol (LDL), and low level of high-density lipoprotein cholesterol (HDL). Dyslipidemia is an important risk factor for cardiovascular disease [6]. Some OCPs, such as HCB, $p$, $p^{\prime}$-dichlorodiphenyldichloroethylene (DDE), and oxychlordane, may alter energy metabolism, which may in turn be linked to metabolic dysfunction [7]. Epidemiology studies have revealed the potential links between internal OCP exposure and serum lipids levels. For example, in a cross-sectional study, participants with elevated levels of organochlorine compounds (i.e., $\mathrm{HCB}, \beta \mathrm{HCH}$, trans-nonachlor, $p, p^{\prime}$-DDT, and $p, p^{\prime}$-DDE) exhibited decreased HDL [8]. Han et al. reported that $p, p^{\prime}$-DDT and mirex/kepone were positively associated with high TG, TC, and LDL [9]. Inflammation is a protective response of vascularized tissues that plays an essential role in host defense against invading agents, infections, and tissue damage [10], manifesting in long-term alterations to systemic levels of immune mediators [11]. Chronic inflammation may predispose various chronic diseases, including cancer $[10,12]$. There is growing interest in identifying specific 
reagents that induce inflammation and inflammation components that are affected by the exposure. It has been reported that $\beta \mathrm{HCH}$, $\mathrm{DDE}$, and dieldrin can induce an inflammatory response in human ovary surface epithelial cells, with pro-inflammatory cytokines such as interleukin (IL)-6, IL-1ß, and tumor necrosis factor (TNF)-a overexpressed [13]. Peinado et al. reviewed published in vitro, in vivo, and epidemiological data and found that there were consistent positive associations between exposure to certain OCPs, such as DDT, DDE, endosulfan, $\beta \mathrm{HCH}$, hexachlorobenzene, aldrin, and dieldrin, and developing a pro-inflammatory milieu [14]. However, epidemiological evidence related to the association between OCP exposure and lipid metabolism and inflammation is still limited $[8,9,14,15]$.

Human exposure to OCPs occurs readily in the environment due to their widespread use in recent decades and their persistence. Foods have consistently been shown to be a dominant source of exposure to the majority of these toxins [16]. Animal findings provide evidence that exposure to these compounds via foods is associated with metabolic disorders and inflammation [17, 18]. As far as we know, however, no study has focused on the associations between dietary OCP intake and lipid metabolism and inflammation in humans. Nutrition in food plays a vital role in human health $[19,20]$, and dietary patterns are correlated with a range of health outcomes [21, 22]. Dietary interventions, specifically, increasing the intake of plant-origin food, are important strategies for preventing or treating metabolic diseases and chronic subclinical inflammation [23,24]. However, the levels of organic pollutants present in plantorigin foods have received less attention in nutritional epidemiology [17]. Comprehensive epidemiological research across the entire food-borne exposome is needed $[4,25]$.

The North China Plain is a typical agricultural region with extensive historical use of OCPs and high levels of environmental residues $[26,27]$. A recent study has reported that residents in a typical wastewater irrigation area in North China have dietary OCPs intake due to maize consumption and dominated by $p, p^{\prime}$-DDT and $y-\mathrm{HCH}$ [28]. When considering the health risks of exposure to OCPs, the pivotal point is that low-dose exposure may be more harmful [29]. In this multiple follow-up study, we examined the associations between dietary OCP intake from plant-origin foods and biomarkers of serum lipids and inflammation in childbearing-age women in North China.

\section{Materials And Methods}

\section{Population Recruitment}

Our multiple follow-up study was conducted in the Mancheng District of Baoding City in Hebei Province, China. The study design and recruitment criteria have been described in detail previously [30]. Briefly, women who had been residents for longer than 2 years, aged between 18 and 50 years old, and without cardiovascular disease, hepatitis, cancer, diabetes, rheumatoid arthritis, chronic renal failure, or chronic lung disease were recruited. The participants were first recruited on January 27, 2015, and were then followed up on four successive occasions, on March 17, 2015, June 8, 2015, January 11, 2016, and April 11, 2016, resulting in a total of five visits. During each visit, we conducted a questionnaire survey, blood collection, and food sampling. We collected information on the women's socialdemographic and lifestyle characteristics, i.e., height, weight, age, residence, occupation, educational background, smoking and passive smoking status, frequency of wine or beer consumption, frequency of staying up late, and exercise. Fasting venous blood samples were mostly collected, and serum was subsequently separated. A total of 35 women were visited on not fewer than three occasions. Among them, 10 women ( 5 in urban areas and 5 in rural areas) were selected for a personal dietary survey during the five visits. These women were asked to complete semi-quantitative food questionnaires covering food consumption frequency and the average amount of food consumed each week throughout the study. This study was approved by the Institutional Review Board of Peking University, and signed informed consent was obtained for each participant.

\section{Intake Levels of OCPs and Nutrients}

Representative plant-based food samples were taken from nearby supermarkets, open fairs, and the participants' homes during each visit. Three major food groups consumed by local women, including cereals, vegetables, and fruits, comprising a total of 275 food samples, were selected for OCP analysis. Target OCPs included $a-\mathrm{HCH}, \beta-\mathrm{HCH}, \gamma-\mathrm{HCH}, \delta-\mathrm{HCH}, p, p^{\prime}-\mathrm{DDT}, p, p^{\prime}-$ dichlorodiphenyldichloroethane (DDD), $p, p^{\prime}-\mathrm{DDE}, o, p^{\prime}-\mathrm{DDT}, o, p^{\prime}$-DDD, $o, p^{\prime}-\mathrm{DDE}$, aldrin, dieldrin, endrin, isodrine, endosulfan- $a$, endosulfan$\beta$, heptachlor, heptachlor epoxide isomer, and mirex. Detailed sample collection and quantification procedures for OCPs are described in the Supplementary Materials (SM).

The estimated dietary intakes (EDIs) of OCPs $\left(\mathrm{ng} \mathrm{kg}^{-1} \mathrm{day}^{-1}\right)$ and nutrients for women were calculated using Eq. (1):

$E D I=\Sigma\left(C_{i} \times I R_{i}\right) / B W(1)$ 
where $C_{i}$ is the concentration of an individual OCP (ng g ${ }^{-1}$ wet weight) or nutrient in a food (SM, Table S2 and S3), $I R_{i}$ is a given woman's intake rate $\left(\mathrm{g} \mathrm{day}^{-1}\right)$ of the food type $(i)$, and $B W$ is the body weight $(\mathrm{kg})$. Values of $C_{i}$ for nutrients were obtained from the China Food Composition survey book [31, 32]. IR and $B W$ values were obtained from the questionnaire responses (SM, Table S4). The food consumption evaluation method is described in detail in the SM.

\section{Serum Biomarkers}

Serum concentrations of lipid biomarkers [i.e., lipoprotein(a) (Lp(a)), TG, TC, HDL, and LDL] and pro-inflammatory biomarkers [i.e., monocyte chemotactic protein-1 (MCP-1) (BD Biosciences), IL-6 (BD Biosciences), and IL-8 (BD Biosciences)] were measured in this study. The detailed quantification methods have been described previously [30].

\section{Data Analysis}

We used means, medians, interquartile ranges (IQRs), and standard deviations (SDs) to describe the data distribution. To improve the normality, the concentrations of serum biomarkers of lipids and inflammation were log-transformed when investigating their associations with dietary OCP and nutrient intakes. Three linear mixed-effect models with a random intercept for each participant were used to estimate the associations between dietary exposure and serum biomarkers as this was a multiple follow-up study, as discussed previously [30]. We also adjusted for a series of potential confounders consisting of population characteristics and living habits in the statistical models, including age, body mass index (BMI), location, occupation, education, smoking, passive smoking, drinking wine, drinking beer, staying up late, and exercise. We estimated the percentage changes [denoted as percent change $(P C \%)]$ and the $95 \%$ confidence intervals (Cls) for serum biomarkers associated with an IQR increase in levels of dietary intake of OCPs or nutrients. The $P C \%$ can be obtained using Eq. (2):

$P C \%=\left[\exp ^{(I Q R \times \beta)}-1\right] \times 100 \%(2)$

where $\beta$ is the coefficient of a given OCP or nutrient in the linear mixed-effect model. The significance level was defined as two-tailed $p$ $<0.05$ throughout this study. Statistical analyses were conducted using the R statistical computing environment (version 4.0.2).

\section{Results}

\section{Population Characteristics}

The population demographics and serum biomarkers of the 10 participants during the five visits are summarized in Table 1, and the serum biomarkers of lipids and inflammation are shown in Table S5. The mean (SD) age of the women was 36.96 (4.90) years, ranging from 27 to 46 years. The scale of participants' BMI was 20.31 to $31.01 \mathrm{~kg} \mathrm{~m}^{-2}$, with a mean (SD) value of 25.45 (2.99) $\mathrm{kg} \mathrm{m}^{-}$

2. All women were ethnic Han in this study. Half the women were well educated, to college level or above. Only one in 10 women reported smoking and drinking wine, but eight in 10 reported exposure to passive smoking and beer consumption.

\section{Associations between OCP Intake and Serum Biomarkers}

Four isomers of $\mathrm{HCHs}$, three congeners of DDT and their metabolites, dieldrin, and two isomers of endosulfans were found with relatively high detection rates of $>30 \%$ and discussed here. The detection rates of other OCPs, such as aldrin, endrin, isodrine, heptachlor, heptachlor epoxide isomer, and mirex, $o, p^{\prime}-\mathrm{DDT}, p, p^{\prime}-\mathrm{DDD}$, and $o, p^{\prime}-\mathrm{DDD}$, were $<30 \%$. For all five visits, the sum of endosulfan- $\alpha$ and endosulfan- $\beta\left(\Sigma \mathrm{ES} ; 8.83 \mathrm{ng} \mathrm{kg}^{-1}\right.$ day $\left.^{-1}\right)$ dominated the dietary intake of the sum of $\alpha-\mathrm{HCH}, \beta-\mathrm{HCH}, \gamma-\mathrm{HCH}, \delta-\mathrm{HCH}$, $p, p^{\prime}-\mathrm{DDT}, p, p^{\prime}-\mathrm{DDE}, o, p^{\prime}-\mathrm{DDE}$, dieldrin, endosulfan- $a$, and endosulfan- $\beta\left(\Sigma \mathrm{OCP} ; 13.5 \mathrm{ng} \mathrm{kg}^{-1} \mathrm{day}^{-1}\right)$, followed by dieldrin $\left(3.47 \mathrm{ng} \mathrm{kg}{ }^{-1}\right.$ day $^{-1}$ ) (Table S6).

The univariate model suggested that intakes of $p, p^{\prime}-\mathrm{DDT}$ and $o, p^{\prime}-\mathrm{DDE}$ were negatively associated with serum concentrations of $\mathrm{HDL}$ with or without adjusting for potential confounders (i.e., age, BMI, location, occupation, education, smoking, passive smoking, drinking wine, drinking beer, staying up late, and exercise), whereas the associations were not statistically significant for serum Lp(a), TG, TC, and LDL (Fig. 1). No robust relationships were found between other individual OCPs and serum lipids. The detailed results are shown in Table S7-S9.

Serum IL- 6 is not shown here because it was not detected in any of the women, so only associations of MCP-1 and IL-8 levels with the dietary intake of OCPs were investigated. Intake of specific OCPs was associated with inflammation biomarkers (Table 2, Figure S1). 
Among them, the dietary intake of dieldrin, endosulfan- $\beta, \Sigma E S$, and $\Sigma O C P$ was found to be positively correlated with serum IL-8, with or without adjusting for population characteristics and living habits. In addition, the intake of $p, p^{\prime}$-DDE was negatively correlated with serum IL-8, although no significant association was found after adjusting for all possible confounders.

\section{Associations between Nutrient Intakes and Serum Biomarkers}

The dietary intake of nutrient is presented in Table S10. No statistically significant associations with dietary nutrient intakes were found for serum lipid levels either with or without adjusting for potential confounders (data not shown). Similarly, no solid association was found between nutrient intakes and serum biomarkers of inflammation (SM, Table S11). Overall, there were no correlations between nutrient intakes and serum biomarkers in this study.

\section{Discussion}

Our study supported the hypothesis that the dietary intake of some OCPs from plant-based foods is associated with interference of serum lipid levels and affects inflammation responses among childbearing-age women in a typical agricultural region. In addition, we did not find any associations between nutrient intakes and serum biomarkers here, which can partly support our findings. The study is the first to assess the potential impacts of dietary OCPs exposure from plant-based foods on serum lipid and inflammation biomarkers using a multiple follow-up study in North China.

We observed overall no associations between nutritional intakes and serum biomarkers among 10 intensively studied women. This is inconsistent with previous studies that reported the potential influence of food nutrients on lipid metabolism and inflammation. Patel et al. identified and validated several environmental factors correlated with TG, LDL, and HDL levels using the National Health and Nutrition Examination Survey (NHANES) [19]. In their study, vitamins A and E were positively associated with TG and LDL but negatively associated with HDL, and carotenoids were associated with lower TG levels and higher levels of both HDL and LDL. As Calder et al. reported, among the components of a healthy diet, whole grains, vegetables, fruits, and fish are all associated with lower inflammation, and vitamin C, vitamin E, and carotenoids decrease circulating concentrations of inflammatory markers [22]. Largescale and long-term survey or dietary intervention methods were used in the previous studies to investigate the links between nutrients and lipid metabolism and inflammation, which was different from our study. Our target population was childbearing-age women recruited in a small county, resulting in a similar dietary pattern between individuals. The women recruited had neither a significant change in dietary structure nor nutritional supplements throughout the study period. Relatively fixed dietary patterns are unlikely to cause obvious inter- and intra-individual variation in levels of lipid and inflammation biomarkers, which may be the reason for the negative results observed in this study. Thus, this can provide a good study scenario to explore the relationship between dietary OCP intake and effect biomarkers.

Cereals, fruits, and vegetables are the primary foods in local diets and comprised more than $75 \%$ of the women's daily food consumption. As reported previously, plant-origin foods may play an important role in exposure to OCPs due to the relatively higher ingestion amounts of such foods [33,34]. Specifically, vegetables dominate the dietary exposure dose for the sum of DDT and its metabolites ( $\Sigma D D T)$ and the sum of $\mathrm{HCH}$ isomers $(\Sigma \mathrm{HCH})$ for the Nanjing population [33]. From this perspective, OCP exposure from plant-origin foods may play an essential role in disturbing the metabolic and immune systems rather than nutrients in our target population. The potential influence of dietary OCP intake by local women on lipid metabolism and inflammation is hence mainly discussed in this context.

In the present study, significant negative links between dietary exposure to $p, p^{\prime}$-DDT and $o, p^{\prime}$-DDE and serum HDL were found. These results suggest that OCPs may disrupt lipid metabolism and contribute to dyslipidemia, which is in line with previous studies. Exposure to persistent organic pollutants, especially OCPs, may alter genome-wide gene transcription related to energy metabolism [7, 17] and induce mitochondrial dysfunction $[35,36]$, thus affecting the metabolites of crucial metabolic processes mainly related to human lipid metabolism [37]. Lee et al. observed significant associations of serum $p, p^{\prime}$-DDE with higher TGs and lower HDL during a 20-year follow-up study [38]. Dusanov et al. also found that participants with elevated levels of organochlorine compounds (i.e., HCB, $\beta-\mathrm{HCH}$, trans-nonachlor, $p, p^{\prime}-\mathrm{DDT}$, and $p, p^{\prime}-\mathrm{DDE}$ ) in serum also exhibited decreased $\mathrm{HDL}$ in a cross-sectional study [8]. Conversely, no association with HDL was observed that could be attributed to DDTs and their metabolites in serum in a case-control study in Shandong Province in East China, although TG, TC, and LDL disturbances were observed in the study [9]. A 5-year prospective analysis from the Prospective Investigation of the Vasculature in Uppsala Seniors (PIVUS) cohort of elderly adults in Sweden found only a positive association between serum $p, p^{\prime}$-DDE and LDL, whereas no significant results were reported for TG, TC, and HDL [39]. The 
discrepancies among various studies may be explained by the variations in population characteristics and living habits, which are inevitably related to lipid metabolism $[5,6,40]$. We have verified that some OCP exposure can be related to interference with blood lipid levels, although there are differences in significantly associated markers across different studies. Here we report the association between dietary OCP exposure due to plant-origin food consumption and lipid metabolism in humans, providing evidence for the influence of long-term low-dose OCP exposure on human lipid metabolism from another perspective.

Furthermore, an association between dietary $o, p^{\prime}$-DDE exposure and serum lipid disorder was found in this study instead of exposure to $p, p^{\prime}$-DDE, which is a major metabolite of $p, p^{\prime}$-DDT that has been commonly considered in previous studies [7, 9]. Qiu et al. had identified dicofol formulation, which contains a high ratio of $o, p^{\prime}-\mathrm{DDT} / p, p^{\prime}-\mathrm{DDT}$, as a key and sometimes dominant DDT source in the air in China in recent years [41]. Therefore, the regulation of $o, p^{\prime}$-DDTs and its epidemiologic study are necessary for population health in China. Further longitudinal studies with measures of OCPs over time are needed.

Our study showed that serum IL-8 was positively associated with dieldrin, endosulfan- $\beta, \Sigma E S$, and $\Sigma O C P$ intake, but negatively associated with $p, p^{\prime}$-DDE intake. IL-8 is a well-known pro-inflammatory cytokine and has been reported to increase in patients with various autoimmune diseases, infections, cancers, and psychiatric diseases [42, 43]. An association between persistent organochlorine pollutant exposure and elevated cytokine levels has been reported [44, 45]. Exposure to endosulfans and dieldrin can increase the expression levels of the pro-inflammatory factors IL-6, IL-8, IL-1 $\beta$, and TNF-a, as evidenced in molecular studies $[13,46]$. Female mice and rats had increased levels of pro-inflammatory cytokines when exposed to doses ranging from 2-50 mg/kg of endosulfans [18,47], which is consistent with our results. However, no significant associations were found between serum dieldrin, endosulfan- $a$, and endosulfan- $\beta$ and cytokines (i.e., IL-2, IL-4, IL-6, and IL-10) in preterm birth cases in a case-control study in India, and only endosulfan- $\beta$ was positively correlated with IL-2 in the controls [48]. The difference can be attributed to the geographic, demographic, and targeted biomarker variances among studies and requires further investigation. Overall, we observed an association between the intake of specific OCPs from plant-origin foods and inflammation factors in this study, indicating a disruption of homeostasis due to these compounds. As far as we know, there is little evidence of the influence of dietary OCP intake on proinflammatory responses from population studies. Considering its various hazardous health outcomes, inflammation caused by the dietary intake of OCPs from plant-origin foods deserves further attention.

The following limitations should be considered when interpreting our results. First, the bioavailability of OCPs among foods was not considered. Second, only limited serum biomarkers of lipids and inflammatory effects were measured. Further comprehensive information is needed to provide an in-depth investigation. However, our study also had several advantages. First, our study focused on dietary ОСР exposure from plant-origin foods in childbearing-age women in a typical agriculture area, providing a unique insight into OCP exposure toxicity. Second, the dietary intake of nutrients was considered simultaneously, providing comprehensive foodborne exposure information. Third, we adopted a multiple follow-up study to effectively reduce the influence of confounders.

\section{Conclusion}

We concluded that dietary intake of some individual DDT-, DDE-, dieldrin-, and endosulfan-class chemicals from plant-origin foods may interfere with lipid metabolism and inflammation responses. To our knowledge, this is the first study to investigate the associations of dietary OCP intake with serum lipid and inflammation biomarkers using a multiple follow-up study in North China. Our results can support related policy for controlling population environmental exposure to OCPs, as well as further our understanding of the potential health effects of OCPs in the population.

\section{Abbreviations}

OCPs, organochlorine pesticides; DDT, dichlorodiphenyltrichloroethane; HCB, hexachlorobenzene; $\mathrm{HCH}$, hexachlorocyclohexane; TG, triglyceride; TC, total cholesterol; LDL, low-density lipoprotein cholesterol; HDL, high-density lipoprotein cholesterol; DDE, dichlorodiphenyldichloroethylene; IL, interleukin; TNF, tumor necrosis factor; DDD, dichlorodiphenyldichloroethane; EDIs, estimated dietary intakes; Lp(a), lipoprotein(a); MCP-1, monocyte chemotactic protein-1; IQRs, interquartile ranges; SDs, standard deviations; BMI, body mass index; $P C \%$, percent change; Cls, confidence intervals; PIVUS, Prospective Investigation of the Vasculature in Uppsala Seniors; NHANES, National Health and Nutrition Examination Survey; $\Sigma \mathrm{HCH}$, the sum of $\alpha-\mathrm{HCH}, \beta-\mathrm{HCH}, \gamma-\mathrm{HCH}$, and $\delta \mathrm{HCH} ; \Sigma \mathrm{DDX}$, the sum of $p, p^{\prime}-\mathrm{DDT}, p, p^{\prime}-\mathrm{DDE}$ and $o, p^{\prime}-\mathrm{DDE}$; DIE, dieldrin; ES1, endosulfan- $\alpha$, ES2, endosulfan- $\beta$; $\Sigma \mathrm{ES}$, the sum of ES1 and ES2; $\Sigma \mathrm{OCP}$, the sum of $\Sigma \mathrm{HCH}, \Sigma \mathrm{DDX}, \mathrm{DIE}$, and $\Sigma \mathrm{ES}$. 


\section{Declarations}

\section{Ethics Approval and Consent to Participate}

This study was approved by the institutional review board of Peking University and the signed informed consent was obtained for each participant.

\section{Consent for Publication}

Not applicable

\section{Availability of Data and Materials}

The data that support the findings of the current study available from the corresponding author on reasonable request.

\section{Competing Interests}

The authors declare that they have no competing interests.

\section{Funding}

This work was supported by the National Natural Science Foundation of China [Grant No. 41401583, 41771527, 81673177, and 41371466].

\section{Authors' Email Addresses}

Xuepeng Wang: wangxp_d@foxmail.com

Miaomiao Gao: gaomm0315@foxmail.com

Yixi Tan: 459816045@qq.com

Qi Li: liqibnu@foxmail.com

Junxi Chen: indychen@pku.edu.cn

Changxin Lan: lancx_pku@foxmail.com

Bahabaike Jiangtulu: bahapku@foxmail.com

Bin Wang: binwangpku@foxmail.com

Yanxin Yu: yuhe_f@sina.com

Zhiwen Li: lizw@bjmu.edu.cn

\section{Authors' Contributions}

Xuepeng Wang: Conceptualization, Methodology, Formal analysis, Visualization, Writing-Original Draft, Writing-Review \& Editing; Bin Wang: Conceptualization, Methodology, Writing-Review \& Editing, Supervision, Project administration, Funding acquisition; Yanxin Yu: Conceptualization, Methodology, Writing-Review \& Editing, Supervision, Funding acquisition; Miaomiao Gao and Qi Li: Investigation, Writing-Review \&Editing; Yixi Tan: Data Curation, Writing-Review \& Editing; Changxin Lan, Junxi Chen and Bahabieke Jiangtulu: Methodology, Software, Writing-Review \& Editing; Zhiwen Li: Writing-Review \& Editing.

\section{Acknowledgement}

All authors would like to express our gratitude to the help from the working group of environmental exposure and human health of the China Cohort Consortium (See http://chinacohort.bjmu.edu.cn/). 


\section{References}

1. Cui Y, Ke R, Gao W, Tian F, Wang Y, Jiang G. Analysis of Organochlorine Pesticide Residues in Various Vegetable Oils Collected in Chinese Markets. J Agric Food Chem. 2020;68(49):14594-602.

2. Stockholm Convention on Persistent Organic Pollutant (POPs). http://chm.pops.int/TheConvention/ThePOPs/tabid/673/Default.aspx.

3. Escher BI, Stapleton HM, Schymanski EL. Tracking Complex Mixtures of Chemicals in Our Changing Environment. Science. 2020;367(6476):388-92.

4. Huang Y, Fang M. Nutritional and Environmental Contaminant Exposure: A Tale of Two Co-Existing Factors for Disease Risks. Environ Sci Technol. 2020;54(23):14793-6.

5. Aminov Z, Carpenter DO. Serum Concentrations of Persistent Organic Pollutants and The Metabolic Syndrome in Akwesasne Mohawks, A Native American community. Environ Pollut. 2020;260:114004.

6. Rosenbaum PF, Weinstock RS, Silverstone AE, Sjodin A, Pavuk M. Metabolic Syndrome is Associated with Exposure to Organochlorine Pesticides in Anniston, AL, United States. Environ Int. 2017;108:11-21.

7. Herst PM, Aars J, Joly Beauparlant C, Bodein A, Dalvai M, Gagne D, Droit A, Bailey JL, Routti H. Adipose tissue transcriptome is related to pollutant exposure in polar bear mother-cub pairs from svalbard, norway. Environ Sci Technol. 2020;54(18):11365-75.

8. Dusanov S, Ruzzin J, Kiviranta H, Klemsdal TO, Retterstol L, Rantakokko P, Airaksinen R, Djurovic S, Tonstad S. Associations Between Persistent Organic Pollutants and Metabolic Syndrome in Morbidly Obese Individuals. Nutr Metab Carbiovasc Dis. 2018;28(7):735-42.

9. Han X, Zhang F, Meng L, Xu Y, Li Y, Li A, Turyk ME, Yang R, Wang P, Zhang J, et al. Exposure to Organochlorine Pesticides and The Risk of Type 2 Diabetes in The Population of East China. Ecotox Environ Safe. 2020;190:110125.

10. Greten FR, Grivennikov SI. Inflammation and Cancer: Triggers, Mechanisms, and Consequences. Immunity. 2019;51(1):27-41.

11. Cox AJ, West NP, Cripps AW. Obesity, Inflammation, and The Gut Microbiota. Lancet Diabetes Endocrinol. 2015;3(3):207-15.

12. Taniguchi K, Karin M. NF-KB, Inflammation, Immunity and Cancer: Coming of Age. Nat Rev Immunol. 2018;18(5):309-24.

13. Shah HK, Sharma T, Banerjee BD. Organochlorine Pesticides Induce Inflammation, ROS production, and DNA Damage in Human Epithelial Ovary Cells: An in vitro Study. Chemosphere. 2020;246:125691.

14. Peinado FM, Artacho-Cordon F, Barrios-Rodriguez R, Arrebola JP. Influence of Polychlorinated Biphenyls and Organochlorine Pesticides on The Inflammatory Milieu. A Systematic Review of in vitro, in vivo and Epidemiological Studies. Environ Res 2020, 186.

15. Suarez-Lopez JR, Clemesha CG, Porta M, Gross MD, Lee DH. Organochlorine Pesticides and Polychlorinated Biphenyls (PCBs) in Early Adulthood and Blood Lipids over a 23-year Follow-up. Environ Toxicol Pharmacol. 2019;66:24-35.

16. Yu Y, Li C, Zhang X, Zhang X, Pang Y, Zhang S, Fu J. Route-specific daily uptake of organochlorine pesticides in food, dust, and air by Shanghai residents, China. Environ Int. 2012;50:31-7.

17. Ruzzin J, Petersen R, Meugnier E, Madsen L, Lock EJ, Lillefosse H, Ma T, Pesenti S, Sonne SB, Marstrand TT, et al. Persistent Organic Pollutant Exposure Leads to Insulin Resistance Syndrome. Environ Health Perspect. 2010;118(4):465-71.

18. Jang T-c, Jang J-h, Lee K-w. Mechanism of Acute Endosulfan Intoxication-induced Neurotoxicity in Sprague-Dawley Rats. Arh Hig Rada Toksikol. 2016;67(1):9-17.

19. Patel CJ, Cullen MR, Ioannidis JP, Butte AJ. Systematic Evaluation of Environmental Factors: Persistent Pollutants and Nutrients Correlated with Serum Lipid Levels. Int J Epidemiol. 2012;41(3):828-43.

20. Mokarizadeh A, Faryabi MR, Rezvanfar MA, Abdollahi M. A comprehensive review of pesticides and the immune dysregulation: Mechanisms, evidence and consequences. Toxicol Mech Methods. 2015;25(4):258-78.

21. Thorburn AN, Macia L, Mackay CR. Diet, Metabolites, and "Western-lifestyle" Inflammatory Diseases. Immunity. 2014;40(6):83342.

22. Calder PC, Ahluwalia N, Brouns F, Buetler T, Clement K, Cunningham K, Esposito K, Jonsson LS, Kolb H, Lansink M, et al. Dietary Factors and Low-grade Inflammation in Relation to Overweight and Obesity. Br J Nutr. 2011;106(Suppl 3):5-78.

23. Shin PK, Park SJ, Kim MS, Kwon DY, Kim MJ, Kim K, Chun S, Lee HJ, Choi SW. A Traditional Korean Diet with a Low Dietary Inflammatory Index Increases Anti-Inflammatory IL-10 and Decreases Pro-Inflammatory NF-KB in a Small Dietary Intervention Study. Nutrients 2020, 12(8). 
24. Castro-Barquero S, Ruiz-Leon AM, Sierra-Perez M, Estruch R, Casas R. Dietary Strategies for Metabolic Syndrome: A Comprehensive Review. Nutrients 2020, 12(10).

25. Vermeulen R, Schymanski EL, Barabasi AL, Miller GW. The Exposome and Health: Where Chemistry Meets Biology. Science. 2020;367(6476):392-6.

26. Yu H, Liu Y, Shu X, Ma L, Pan Y. Assessment of The Spatial Distribution of Organochlorine Pesticides (OCPs) and Polychlorinated Biphenyls (PCBs) in Urban Soil of China. Chemosphere. 2020;243:125392.

27. Li Q, Lu Y, Wang P, Wang T, Zhang Y, Suriyanarayanan S, Liang R, Baninla Y, Khan K. Distribution, Source, and Risk of Organochlorine Pesticides (OCPs) and Polychlorinated Biphenyls (PCBs) in Urban and Rural Soils around The Yellow and Bohai Seas, China. Environ Pollut. 2018;239:233-41.

28. Xi B, Yu M, Zhang Y, Gao R, Zhang H, Li D, Tan W, Hou H, Yu H. Residues and Health Risk Assessments of Organochlorine Pesticides in a Typical Wastewater Irrigation Area of North China. Asian Journal of Ecotoxicology. 2016;11(2):453-64.

29. Lee YM, Kim KS, Kim SA, Hong NS, Lee SJ, Lee DH. Prospective Associations between Persistent Organic Pollutants and Metabolic Syndrome: A Nested Case-control Study. Sci Total Environ. 2014;496:219-25.

30. Chen J, Lan C, An H, Jin Y, Li Q, Ge S, Yu Y, Shen G, Pan B, Xu Y, et al: Potential Interference on The Lipid Metabolisms by Serum Copper in a Women Population: A Repeated Measurement Study. Sci Total Environ 2020:143375-143375.

31. Yang Y, Wang G, Pan X. China Food Composition 2002. Beijing: Peking University Medical Press; 2002.

32. Yang Y, He M, Pan X. China Food Composition 2004. Beijing: Peking University Medical Press; 2005.

33. Zhang QQ, Xia ZH, Wu MM, Wang LP, Yang H. Human health risk assessment of DDTs and HCHs through dietary exposure in Nanjing, China. Chemosphere. 2017;177:211-6.

34. Fang Y, Nie Z, Yang Y, Die Q, Liu F, He J, Huang Q. Human health risk assessment of pesticide residues in market-sold vegetables and fish in a Northern metropolis of China. Environ Sci Pollut Res. 2015;22(8):6135-43.

35. Ko E, Choi M, Shin S. Bottom-line Mechanism of Organochlorine Pesticides on Mitochondria Dysfunction Linked with Type 2 Diabetes. J Hazard Mater. 2020;393:122400.

36. Yu X, Yu RQ, Zhang X, Zhan F, Sun X, Wu Y. DDT Exposure Induces Cell Cycle Arrest and Apoptosis of Skin Fibroblasts from IndoPacific Humpback Dolphin via Mitochondria Dysfunction. Aquat Toxicol. 2019;213:105229.

37. Salihovic S, Ganna A, Fall T, Broeckling CD, Prenni JE, van Bavel B, Lind PM, Ingelsson E, Lind L. The Metabolic Fingerprint of p,p'DDE and HCB Exposure in Humans. Environ Int. 2016;88:60-6.

38. Lee DH, Steffes MW, Sjodin A, Jones RS, Needham LL, Jacobs DR Jr. Low Dose Organochlorine Pesticides and Polychlorinated Biphenyls Predict Obesity, Dyslipidemia, and Insulin Resistance among People Free of Diabetes. PLoS One. 2011;6(1):e15977.

39. Penell J, Lind L, Salihovic S, van Bavel B, Lind PM. Persistent Organic Pollutants Are Related to The Change in Circulating Lipid Levels During a 5 year Follow-up. Environ Res. 2014;134:190-7.

40. Aminov Z, Haase R, Olson JR, Pavuk M, Carpenter DO, Anniston Environmental Health Research C. Racial Differences in Levels of Serum Lipids and Effects of Exposure to Persistent Organic Pollutants on Lipid Levels in Residents of Anniston, Alabama. Environ Int. 2014;73:216-23.

41. Qiu X, Zhu T. Using the o,p'-DDT/p,p'-DDT ratio to identify DDT sources in China. Chemosphere. 2010;81(8):1033-8.

42. Tsai S-J. Role of Interleukin 8 in Depression and Other Psychiatric Disorders. Prog Neuro-Psychopharmacol Biol Psychiatry. 2021;106:110173-3.

43. Lippitz BE. Cytokine Patterns in Patients with Cancer: A Systematic Review. Lancet Oncol. 2013;14(6):e218-28.

44. Imbeault P, Findlay CS, Robidoux MA, Haman F, Blais JM, Tremblay A, Springthorpe S, Pal S, Seabert T, Kruemmel EM, et al: Dysregulation of Cytokine Response in Canadian First Nations Communities: Is There an Association with Persistent Organic Pollutant Levels? PLoS One 2012, 7(7).

45. Bourque J, Desforges JP, Levin M, Atwood TC, Sonne C, Dietz R, Jensen TH, Curry E, McKinney MA. Climate-associated Drivers of Plasma Cytokines and Contaminant Concentrations in Beaufort Sea polar bears (Ursus maritimus). Sci Total Environ. 2020;745:140978.

46. Li S, Xu D, Guo J, Sun Y. Inhibition of Cell Growth and Induction of Inflammation by Endosulfan in HUVEC-C Cells. Environ Toxicol. 2016;31(12):1785-95. 
47. Cecilia Tellez-Banuelos M, Haramati J, Franco-Topete K, Peregrina-Sandoval J, Franco-Topete R, Zaitseva GP. Chronic Exposure to Endosulfan Induces Inflammation in Murine Colon via $\beta$-catenin Expression and IL-6 Production. J Immunotoxicol.

2016;13(6):842-9.

48. Mustafa M, Garg N, Banerjee BD, Sharma T, Tyagi V, Dar SA, Guleria K, Ahmad RS, Vaid N, Tripathi AK. Inflammatory-mediated Pathway in Association with Organochlorine Pesticides Levels in The Etiology of Idiopathic Preterm Birth. Reprod Toxicol. 2015;57:111-20.

\section{Tables}

Table 1. Characteristics of the recruited childbearing-age women in North China 


\begin{tabular}{|c|c|}
\hline Characteristics & Target population $(\mathrm{N}=10)$ \\
\hline Age (years) & $35.96(4.90 ; 27-46)^{\mathrm{a}}$ \\
\hline $\mathrm{BMI}^{\mathrm{b}}\left(\mathrm{kg} \mathrm{m}^{-2}\right)$ & $25.45(2.99 ; 20.31-31.01)^{a}$ \\
\hline \multicolumn{2}{|l|}{ BMI (\%) } \\
\hline Normal $(18.5 \leq \mathrm{BMI}<25)$ & $4(40)$ \\
\hline Overweight (BMI > 25) & $6(60)$ \\
\hline \multicolumn{2}{|l|}{ Location (\%) } \\
\hline Rural & $5(50)$ \\
\hline County & $5(50)$ \\
\hline \multicolumn{2}{|l|}{ Occupation (\%) } \\
\hline Farmer & $2(20)$ \\
\hline Worker & $3(30)$ \\
\hline Technician & $5(50)$ \\
\hline \multicolumn{2}{|l|}{ Education (\%) } \\
\hline Junior middle school & $1(10)$ \\
\hline High school & $4(40)$ \\
\hline College or above & $5(50)$ \\
\hline \multicolumn{2}{|l|}{ Active smoking (\%) } \\
\hline No & $9(90)$ \\
\hline Yes & $1(10)$ \\
\hline \multicolumn{2}{|l|}{ Passive smoking (\%) } \\
\hline No & $2(2)$ \\
\hline Yes & $8(80)$ \\
\hline \multicolumn{2}{|l|}{ Drinking-wine } \\
\hline NO & $9(90)$ \\
\hline YES & $1(10)$ \\
\hline \multicolumn{2}{|l|}{ Drinking-beer } \\
\hline NO & $2(20)$ \\
\hline YES & $8(80)$ \\
\hline \multicolumn{2}{|l|}{ Follow-up times (\%) } \\
\hline 4 & $4(40)$ \\
\hline 5 & $6(60)$ \\
\hline \multicolumn{2}{|c|}{${ }^{\text {a }}$ Data are presented as the mean (standard deviation; minimum-maximum) } \\
\hline${ }^{\mathrm{b}}$ Body mass index & \\
\hline
\end{tabular}

Table 2. Associations between dietary intake levels of organochlorine pesticides with biomarkers of inflammation among the women 


\begin{tabular}{|c|c|c|c|c|c|c|c|c|c|c|c|c|c|c|c|c|c|c|}
\hline \multirow{3}{*}{$\begin{array}{l}\text { OCPs } \\
\text { a }\end{array}$} & \multicolumn{6}{|c|}{ Model- $\square$} & \multicolumn{6}{|c|}{ Model- $\square$} & \multicolumn{6}{|c|}{ Model-口 } \\
\hline & \multicolumn{3}{|c|}{ MCP-1 ${ }^{b}$} & \multicolumn{3}{|l|}{ IL-8 } & \multicolumn{3}{|l|}{ MCP-1 } & \multicolumn{3}{|l|}{ IL-8 } & \multicolumn{3}{|l|}{ MCP-1 } & \multicolumn{3}{|l|}{ IL-8 } \\
\hline & $\beta^{c}$ & $\begin{array}{l}P C(\%) \\
\mathrm{d}\end{array}$ & $p$ & $\beta$ & $P C(\%)$ & $p$ & $\beta$ & $P C(\%)$ & $p$ & $\beta$ & $P C(\%)$ & $p$ & $\beta$ & $P C(\%)$ & $p$ & $\beta$ & $P C(\%)$ & $p$ \\
\hline $\begin{array}{l}\alpha- \\
\mathrm{HCH}\end{array}$ & 0.059 & 3.26 & 0.484 & 0.078 & 4.36 & 0.825 & -0.011 & -0.60 & 0.894 & -0.063 & -3.38 & 0.882 & 0.000 & 0.00 & 1.000 & 0.140 & 7.93 & 0.773 \\
\hline $\begin{array}{l}\beta- \\
\mathrm{HCH}\end{array}$ & 0.232 & 2.40 & 0.589 & 1.070 & 11.6 & 0.532 & -0.096 & -0.97 & 0.819 & 0.522 & 5.49 & 0.809 & -0.010 & -0.11 & 0.983 & 1.809 & 20.3 & 0.457 \\
\hline $\begin{array}{l}\delta- \\
\mathrm{HCH}\end{array}$ & 0.313 & 2.95 & 0.506 & 0.468 & 4.45 & 0.811 & -0.050 & -0.46 & 0.913 & -0.397 & -3.63 & 0.867 & 0.006 & 0.06 & 0.991 & 0.980 & 9.55 & 0.716 \\
\hline$\Sigma \mathrm{HCH}$ & 0.033 & 2.97 & 0.499 & 0.058 & 5.18 & 0.780 & -0.007 & -0.64 & 0.880 & -0.027 & -2.35 & 0.913 & 0.000 & 0.00 & 1.000 & 0.104 & 9.50 & 0.714 \\
\hline $\begin{array}{l}p, p^{\prime} \\
\text { DDT }\end{array}$ & -12.26 & -5.46 & 0.176 & -25.66 & -11.1 & 0.497 & -10.44 & -4.67 & 0.200 & -30.04 & -12.9 & 0.479 & -3.990 & -1.81 & 0.703 & -34.26 & -14.5 & 0.502 \\
\hline $\begin{array}{l}p, p^{\prime} \\
\text { DDE }\end{array}$ & -0.561 & -7.33 & 0.045 & -2.470 & -28.5 & 0.039 & -0.396 & -5.24 & 0.124 & -2.692 & -30.6 & 0.041 & -0.228 & -3.05 & 0.502 & -2.441 & -28.2 & 0.136 \\
\hline$\Sigma$ DDX & -0.512 & -6.59 & 0.047 & -2.093 & -24.3 & 0.058 & -0.371 & -4.83 & 0.117 & -2.294 & -26.3 & 0.059 & -0.209 & -2.75 & 0.503 & -2.115 & -24.6 & 0.160 \\
\hline DIE & 0.020 & 3.78 & 0.553 & 0.250 & 57.9 & 0.041 & -0.019 & -3.46 & 0.579 & 0.390 & 104 & 0.011 & 0.009 & 1.73 & 0.813 & 0.383 & 101 & 0.053 \\
\hline ES1 & 0.002 & 0.47 & 0.936 & 0.052 & 17.1 & 0.469 & -0.019 & -5.73 & 0.302 & 0.045 & 14.8 & 0.635 & 0.002 & 0.73 & 0.913 & 0.160 & 62.2 & 0.138 \\
\hline ES2 & 0.038 & 13.7 & 0.089 & 0.249 & 134 & 0.002 & 0.024 & 8.69 & 0.237 & 0.361 & 243 & 0.000 & 0.028 & 10.0 & 0.288 & 0.446 & 359 & 0.001 \\
\hline$\Sigma$ ES & 0.011 & 6.14 & 0.346 & 0.083 & 55.9 & 0.045 & -0.001 & -0.72 & 0.909 & 0.136 & 107 & 0.010 & 0.008 & 4.31 & 0.554 & 0.160 & 137 & 0.018 \\
\hline$\Sigma O C P$ & 0.007 & 4.69 & 0.405 & 0.053 & 44.1 & 0.065 & -0.002 & -1.57 & 0.776 & 0.084 & 78.5 & 0.021 & 0.004 & 2.84 & 0.652 & 0.096 & 93.4 & 0.035 \\
\hline
\end{tabular}

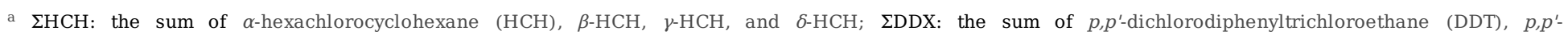

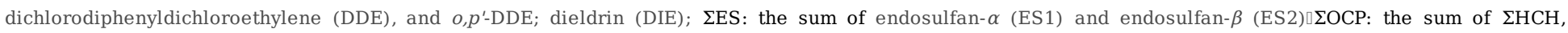
¿DDX, DIE, and $\Sigma E S$.

b MCP-1, monocyte chemotactic protein-1; IL-8, interleukin-8.

${ }^{\mathrm{c}}$ The coefficient of OCPs in the linear mixed-effect model

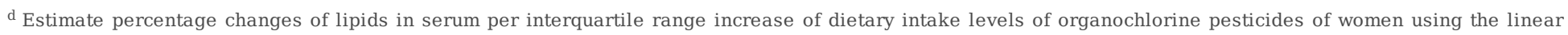
mixed-effect model. Three linear mixed-effect models were used as follows:

Model-₫: Linear mixed-effect model without adjustments;

Model-๑: Linear mixed-effect model with adjustments for age, BMI, location, occupation, education;

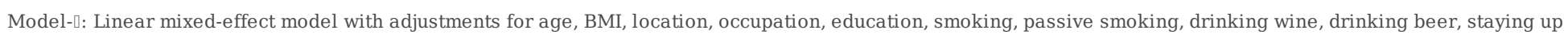
late, and exercise.

\section{Figures}




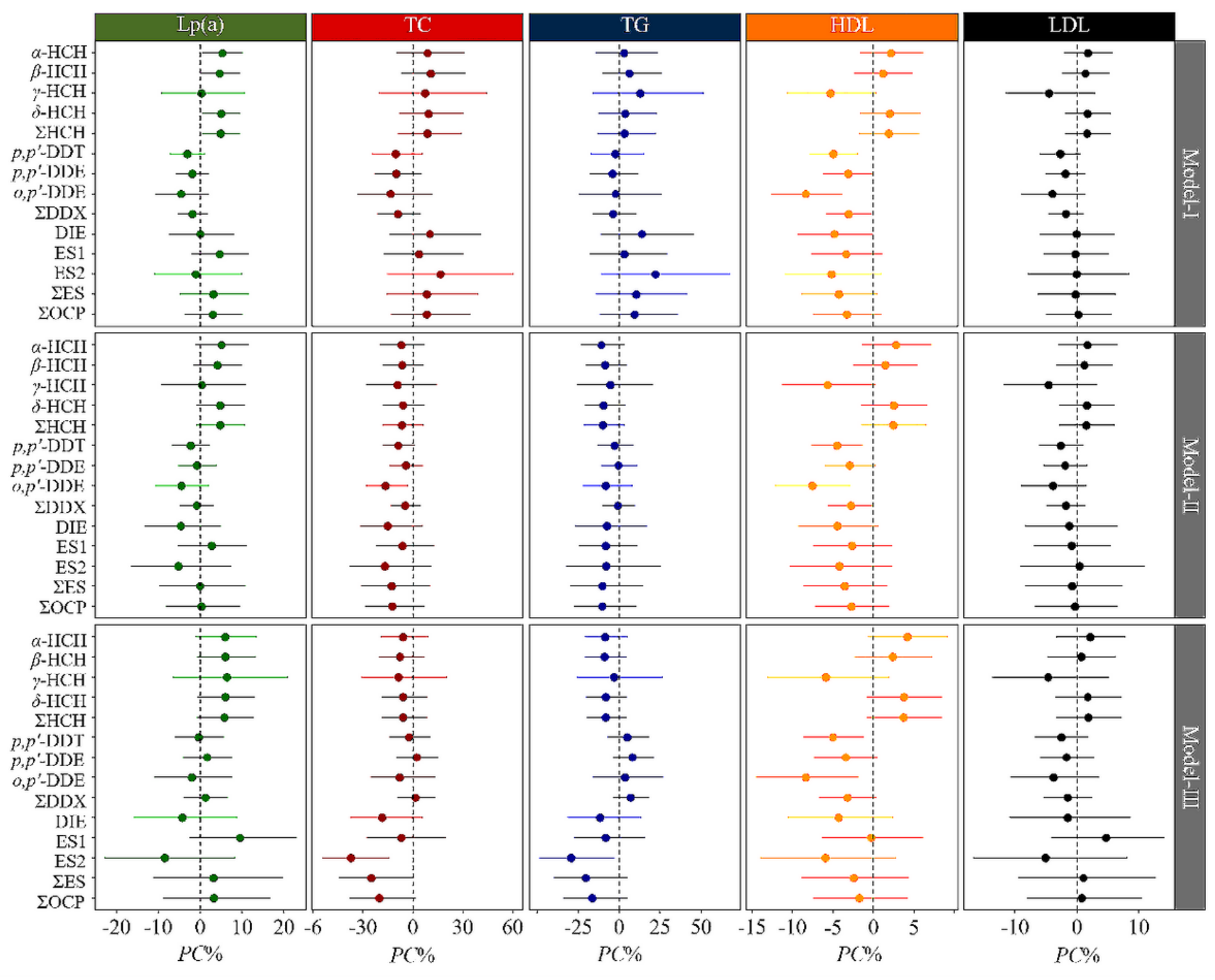

Figure 1

Associations of intakes levels of organochlorine pesticides with serum lipids among the recruited childbearing-age women. $L p(a)$, lipoprotein(a); TC, total cholesterol; TG, triglycerides; HDL, high-density lipoprotein cholesterol; LDL, low-density lipoprotein cholesterol. Three linear mixed-effect models were used as follows: Model-邓: Linear mixed-effect model without adjustments; Model-ख: Linear mixed-effect model with adjustments for age, BMI, location, occupation, education; Model-囚: Linear mixed-effect model with adjustments for age, BMI, location, occupation, education, smoking, passive smoking, drinking wine, drinking beer, staying up late, and exercise. $\Sigma \mathrm{HCH}$ : the sum of a-hexachlorocyclohexane $(\mathrm{HCH}), \beta-\mathrm{HCH}, \mathrm{\gamma}-\mathrm{HCH}$, and $\delta-\mathrm{HCH} ; \Sigma D D X$ : the sum of p,p'-

dichlorodiphenyltrichloroethane (DDT), p,p'-dichlorodiphenyldichloroethylene (DDE), and o,p'-DDE; dieldrin (DIE); $\Sigma$ ES: the sum of endosulfan- $\alpha(E S 1)$ and endosulfan- $\beta$ (ES2) $\varangle \Sigma O C P$ : the sum of $\Sigma H C H, \Sigma D D X, D I E$, and $\Sigma E S$.

\section{Supplementary Files}

This is a list of supplementary files associated with this preprint. Click to download.

- GraphicalAbstract.png

- SupplementaryMaterials.docx 